Revista Tecné, Episteme y Didaxis: TED. Año 2014, Número Extraordinario. ISSN Impreso: 0121-3814, ISSN web: 2323-0126

Memorias, Sexto Congreso Internacional sobre Formación de Profesores de Ciencias. 08 al 10 de octubre de 2014, Bogotá

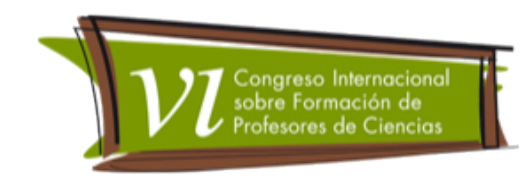

\title{
Investigação de Terminologias Científicas de Química em Língua 'Brasileira de Sinais em Escola Bilíngue de Curitiba, Brasil
}

Stadler, João Paulo'; Filietaz, Marta Rejane Proença2; Hussein, Fabiana R. G. e Silva ${ }^{3}$

Categoria 2: Trabalho de Investigação

\section{Resumo}

Entender como ocorre a sinalização de termos científicos durante o processo de ensino e aprendizagem de Surdos é de extrema importância devido à origem e à pouca mutação desses termos nas línguas orais. Diante disso, investigou-se a sinalização de 20 termos químicos usados por uma professora bilíngue de Curitiba, Brasil, de modo a indicar como são compostos os sinais não oficializados nessa área. Observou-se que a criação de sinais ocorre em grupos fechados, dificultando a divulgação, amplificação e normatização de uso em diferentes escolas no país, indicando a necessidade de uma reunião de Surdos para a criação de sinais específicos uniformizados.

Palavras-chave: ensino de Surdos, sinais específicos, Libras

\section{Objetivo}

Investigar como é composta a sinalização, em Língua Brasileira de Sinais (Libras), de termos específicos dos conteúdos químicos, no contexto de uma escola bilíngue na cidade de Curitiba, Brasil.

\section{Marco Teórico}

As terminologias científicas, na maioria dos casos, derivam de radicais gregos e latinos que, em combinação com palavras de origem grega, latina, inglesa e francesa formam significadas e são incorporadas ao léxico (CANO, 1998). Araújo, Martins e Silva (2011) abordam outros meios de formação de palavras como acrônimos (composição baseada em algumas letras da palavra original) e

\footnotetext{
1 Universidade Tecnológica Federal do Paraná - jp.stadler@gmail.com

2 Universidade Tecnológica Federal do Paraná - martafilietaz@hotmail.com

3 Universidade Tecnológica Federal do Paraná - fabianah@utfpr.edu.br
} 
Revista Tecné, Episteme y Didaxis: TED. Año 2014, Número Extraordinario. ISSN Impreso: 0121-3814, ISSN web: 2323-0126

Memorias, Sexto Congreso Internacional sobre Formación de Profesores de Ciencias. 08 al 10 de octubre de 2014, Bogotá

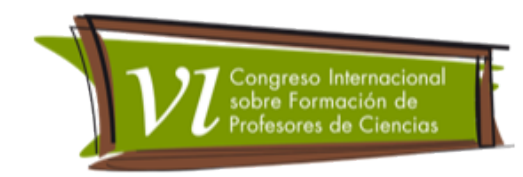

formação de palavras compostas com adjetivos, de modo a restringir um substantivo existente.

A importância do entendimento da formação dos termos científicos se justifica devido ao desenvolvimento científico e tecnológico que precisa ser abordado nas escolas. Uma vantagem para o estudo desses termos dá-se ao fato de que, em geral, ficam restritos a um grupo fechado de usuários evitando transformação ortográfica e/ou sintática observados em itens lexicais da língua popular (CANO, 1998).

A criação de sinais em Libras, segundo Sperb e Laguna (2012) ocorrem, em geral, durante reuniões entre Surdos, que, a partir de um conceito, atribuem sinais ou composições que os explicam o mais completamente possível. Após a decisão, o sinal é utilizado pela comunidade reunida e recomendado à sociedade que 0 incorpora gradualmente. De acordo com Lindino, Steibach e Oliveira (2009), a falta de sinais específicos em Libras decorre do fato da complexidade encontrada na criação desses, interferindo na apresentação dos conceitos para alunos Surdos, tanto por professores bilíngues como por tradutores e intérpretes (TILS).

Para a criação de um sinal, existem características técnicas regulamentadas considerando cinco pontos principais relacionados com a estrutura da língua (MARINHO, 2007):

a) Configuração de mão (CM): formato da mão;

b) Ponto de articulação (PA): região de execução;

c) Movimento (M): movimento das mãos;

d) Orientação da mão (OM): posição da palma da mão;

e) Expressões Não-Manuais (ENM): movimento do corpo e expressões faciais.

A Libras está sujeita a neologismos (criação de novos sinais) que resultam do contato de uma comunidade surda com as outras comunidades surdas ou comunidades ouvintes culminando na de criação de sinais por empréstimos, como o uso da primeira letra da palavra em português como parte do sinal, não sendo baseados, necessariamente, na relação viso-espacial que relaciona 0 conceito com aspectos visuais (SPERB e Laguna, 2012). 
Revista Tecné, Episteme y Didaxis: TED. Año 2014, Número Extraordinario. ISSN Impreso: 0121-3814, ISSN web: 2323-0126

Memorias, Sexto Congreso Internacional sobre Formación de Profesores de Ciencias. 08 al 10 de octubre de 2014, Bogotá

Souza e Silveira (2011) relatam que, em geral, durante as aulas, os intérpretes acabam por criar sinais específicos a partir de seu entendimento do que é proposto pelo professor e, na maioria das vezes, não há qualquer interação entre o intérprete e o professor ou Surdos para verificar a validade conceitual do sinal criado, o que pode prejudicar o processo de ensino e aprendizagem.

Os trabalhos de Silva e Silva (2012), Vales (2008) e Marinho (2007) promoveram a criação de novos sinais em sala de aula, motivados pela necessidade de aperfeiçoar o processo de ensino e aprendizagem, evitando soletrar a palavra e sem usar sinais parecidos que não denotassem conceitos desejados.

No caso de Silva e Silva (2012), os alunos do curso de informática se reuniram com o professor para criar sinais específicos para o uso do editor de texto com 0 objetivo de facilitar a passagem das instruções pelo professor. Os sinais foram estabelecidos respeitando as regras gramaticais e contaram com a influência visual relacionada à interface do programa.

No segundo (Vales, 2008), a criação dos sinais ocorreu em reuniões com a pesquisadora e quatro professoras de Arte, na qual se estabeleceu quais sinais seriam utilizados nas aulas.

No último (Marinho, 2007), foram desenvolvidos os sinais de Biologia em aulas e discussões com a pesquisadora, os alunos e as TILS da escola, priorizando as ideias que os alunos apresentaram.

No caso da Química, Souza e Silveira (2011) afirmam que há escassez de sinais específicos nos dicionários, dificultando a passagem do conceito entre professor, TILS e aluno. Por isso, publicaram uma série de sinais específicos que pretendem melhorar o processo de ensino e aprendizagem bilíngue.

\section{Metodologia}

De acordo com os pressupostos citados por Oliveira (2013), este trabalho pode ser caracterizado como um estudo de caso único que visa à descrição do processo de sinalização de termos espefícios de Química em Libras em uma escola bilíngue da cidade de Curitiba.

O estudo foi realizado em três etapas: 
Revista Tecné, Episteme y Didaxis: TED. Año 2014, Número Extraordinario. ISSN Impreso: 0121-3814, ISSN web: 2323-0126

Memorias, Sexto Congreso Internacional sobre Formación de Profesores de Ciencias. 08 al 10 de octubre de 2014, Bogotá

1) A primeira etapa consistiu no envio de questionário eletrônico, para e-mail pessoal, para um professor bilíngue (profissional que domina o conteúdo da disciplina e é fluente em Libras, sendo capaz de transmitir conhecimento na língua do Surdo) e três TILS (profissional certificado que atua na tradução entre Português e Libras, mediando a transmissão de conhecimento entre professor e aluno Surdo) atuantes na cidade de Curitiba, Brasil, com o objetivo de elencar quais são os principais termos específicos de Química que não apresentavam sinais conhecidos pelos sujeitos;

2) A segunda compreendeu a análise de dois dicionários físicos e um virtual que são tidos como referência em Libras: Capovilla \& Raphael(201 1); Brandão(2011) e Lira \& Souza(2008), para verificar se os termos possuíam alguma definição oficial;

3) A terceira refere-se à entrevista na qual um professor bilíngue foi convidado a representar como são sinalizados os termos específicos apontados.

A quantidade de professores consultados deveu-se ao pequeno número de escolas com a perspectiva bilíngue para Surdos em Curitiba, sendo que todos os profissionais que trabalhavam com Química, em ambos os casos, foram consultados.

\section{Resultados e Discussões}

O primeiro resultado refere-se ao questionário enviado aos professores e TILS, cujo objetivo foi a identificação dos principais termos específicos de Química que não possuíam sinais em Libras. Abaixo estão relacionados os termos citados mais de uma vez nos questionários.

1) Reação Química

2) Reagentes

3) Produtos

4) Ligação lônica

5) Ligação Covalente

6) Molécula
7) Solubilizar/Solubilidade

8) Energia

9) Destilação Simples

10) Hidrocarboneto

11) Densidade

12) Eletronegatividade 
Revista Tecné, Episteme y Didaxis: TED. Año 2014, Número Extraordinario. ISSN Impreso: 0121-3814, ISSN web: 2323-0126

Memorias, Sexto Congreso Internacional sobre Formación de Profesores de Ciencias. 08 al 10 de octubre de 2014, Bogotá

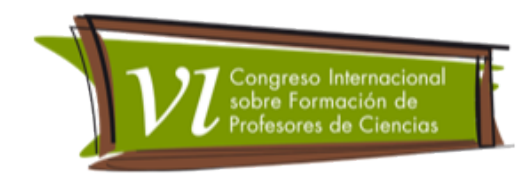

13) Ionização

14) Dissociação

15) Concentração

16) Grupo funcional
17) Fórmula estrutural

18) Pipeta

19) Proveta

20) Erlenmeyer

Em seguida, esses termos foram submetidos a uma análise bibliográfica em dicionários de Libras para verificar a existência de sinalização. A análise apontou apenas três termos listados de forma parecida nos três dicionários, como descritos a seguir:

- O primeiro foi produto relacionado ao sinal produção, sendo definido como: resultado, produto, o que foi realizado;

- O segundo foi energia, que aparece relacionado com o sinal e definição de força e eletricidade;

- O terceiro termo foi concentração, que é definida como juntar-se a outras pessoas em um mesmo ponto ou lugar; reunir-se.

Diante da inexistência de referências oficiais para os termos, prosseguiu-se para a terceira etapa: entrevista na qual um professor bilíngue foi convidado a sinalizar os termos descritos de acordo com sua prática. Os termos foram definidos com os alunos, em sala de aula (Tabela 1), para que fosse verificado qual o processo de elaboração de terminologias foi utilizado conforme o código: 1) Substantivo restrito por adjetivo; 2) Prefixação; 3) Acrônimo ou 4) Empréstimo (Soletração).

Nessa tabela, os termos em letra maiúscula significam sinais existentes no léxico da Libras e letras separadas por hífen representam datilologia.

Tabela 1: Sinalização dos termos químicos

\begin{tabular}{ccc}
\hline Termo Específico & Sinalização & Processo de Criação \\
\hline Reação Química & TRANSFORMAÇÃO + QUÍMICA & 1 \\
Reagentes & $R$ & 3 \\
Produtos & $P$ & 3 \\
\hline
\end{tabular}


Revista Tecné, Episteme y Didaxis: TED. Año 2014, Número Extraordinario. ISSN Impreso: 0121-3814, ISSN web: 2323-0126

Memorias, Sexto Congreso Internacional sobre Formación de Profesores de Ciencias. 08 al 10 de octubre de 2014, Bogotá

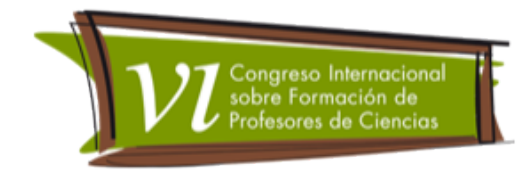

\begin{tabular}{ccc}
\hline \hline & & \\
\hline Ligação lônica & UNIR I-O-N & 3 \\
Ligação Covalente & UNIR C-O-V-A-L-E-N-T-E & 3 \\
Molécula & COISA & $*$ \\
Solubilizar/Solubilidade & DISSOLVER & $*$ \\
Energia & H-C & 1,3 \\
Hidrocarboneto & PESADO & 3 \\
Densidade & E & $*$ \\
Eletronegatividade & MAIS/MENOS + MENOS (MATEMÁTICA) & $*$ \\
lonização & FAZERÍ-O-N & $*$ \\
Dissociação & SEPARAR Í-O-N & $*$ \\
Concentração & FORTE/FRACO & 1 \\
Grupo funcional & FÓRMULA + GRUPO & 1 \\
Fórmula estrutural & FÓRMULA + ESTENDER & $*$ FIDADE \\
\hline
\end{tabular}

Pode-se perceber que os principais processos de elaboração de sinais específicos ocorrem pela restrição de um substantivo por um adjetivo - como apontado por Araújo et al. (2011) - utilizando termos que existem em Libras ou, como o processo relatado por Sperb e Laguna (2012), com o empréstimo de letras ou soletração de termo em Português. Em muitos casos - indicados na tabela por "*" - não houve sinalização específica, mas relação com outras palavras do vocabulário dos Surdos. Os termos Pipeta, Proveta e Erlenmeyer são sinalizados conforme a descrição física do objeto, por meio de classificadores, assim como o termo Destilação Simples, que consiste na representação do fenômeno visto em laboratório.

Dois dos sinais apresentados pela professora foram apresentados, também, por Souza e Silveira (2011): substância e transformação. O sinal de transformação (ou mudança) existe no léxico de Libras e, portanto, é o mesmo nos dois casos; mas o sinal de substância, como não se encontra nos dicionários, é apresentado de maneira diferente pelos dois sinalizadores, indicando a necessidade de padronização de sinais específicos. 
Revista Tecné, Episteme y Didaxis: TED. Año 2014, Número Extraordinario. ISSN Impreso: 0121-3814, ISSN web: 2323-0126

Memorias, Sexto Congreso Internacional sobre Formación de Profesores de Ciencias. 08 al 10 de octubre de 2014, Bogotá

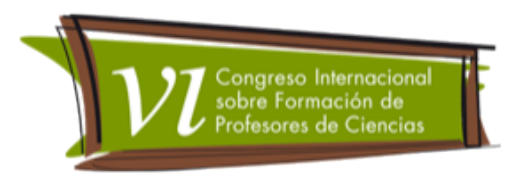

\section{Conclusões}

Mesmo sem oficialização dos termos científicos em dicionários de referência para a Libras, a necessidade de facilitar a tradução e interpretação e de ensinar conceitos, verificado nesse estudo de caso, resulta na criação de sinais dentro de grupos, sem o rigor científico esperado para a elaboração de termos químicos, mesmo em Libras.

Sendo assim, esse estudo indica a necessidade de criar um sistema desenvolvido por vários grupos de Surdos, que pode ser a melhor opção para o desenvolvimento de sinais específicos aceitos e que poderiam ser divulgados amplamente, diminuindo os problemas de comunicação e podendo ser gradativamente adicionados ao léxico dessa língua.

Em trabalho futuro, pretende-se reforçar a indicação acima ao avaliar se, entre diferentes grupos de professores e TILS, há diferença na sinalização de termos específicos, como visto resumidamente nesse artigo.

\section{Referências bibliográficas}

Araújo, M., Martins, P. I., \& Silva, W. S. (2011). Estudando a Terminologia das Ciências Naturais: As Composições em Revistas de Divulgação Científica. Cadernos de Terminologia.

Bradão, F. (2011). Dicionário llustrado de Libras: Língua Brasileira de Sinais. São Paulo: Global.

Cano, W. M. (1998). Prefixação no Vocabulário Técnico-científico. O estado da arte nas ciências do léxico: lexicologia, lexicografia e terminologia.

Capovilla, F. C., \& Rapael, W. D. (2011). Dicionário Enciclopédico llustrado Trilíngue da Língua de Sinais Brasileira. São Paulo: EDUSP.

Lindino, T. C., Steinbach, G. M., \& Oliveira, R. C. (2009). Química para discentes surdos: uma linguagem peculiar. Trama.

Lira, G. D., \& Souza, T. A. (2008). Dicionário de Língua Brasileira de Sinais. Acesso em 19 de março de 2014, disponível em AcessoBrasil: http://www.acessobrasil.org.br/libras/ 
Revista Tecné, Episteme y Didaxis: TED. Año 2014, Número

Extraordinario. ISSN Impreso: 0121-3814, ISSN web: 2323-0126

Memorias, Sexto Congreso Internacional sobre Formación de Profesores de Ciencias. 08 al 10 de octubre de 2014, Bogotá

Marinho, M. L. (2007). O Ensino de Biologia: O intérprete e a geração de sinais.Dissertação de Mestrado, Universidade de Brasília, Brasília, DF, Brasil.

Oliveira, M. M. (2013). Como Fazer uma Pesquisa Qualitativa. Petrópolis: Vozes.

Silva, V., \& Silva, F. I. (2012). criação de novos sinais na disciplina de informática do curso de educação de. Núcleo de Estudos e Pesquisas .

Souza, S. F., \& Silveira, H. E. (2011). Terminologias Químicas em Libras: A Utilização de Sinais na Aprendizagem. Química Nova na Escola.

Sperb, C. C., \& Laguna, M. C. (2010). Os Sinalários na Língua de Sinais: . In: XI Encontro do CELESUL.

Vales, L. D. (2008). Pequeno Dicionário Regional de Libras para Artes. Monografia de Especialização, Universidade Federal do Rio Grande do Sul, Porto Alegre, RS, Brasil 